\title{
Multivariate ordination identifies vegetation types associated with spider conservation in brassica crops
}

\author{
Hafiz Sohaib Saqib ${ }^{1,2}$, Minsheng You ${ }^{1,2,3}$, Geoff M Gurr ${ }^{\text {Corresp. 1, 2, 3, } 4}$ \\ 1 Institute of Applied Ecology, Fujian Agriculture \& Forestry University, Fuzhou, Fujian, China \\ 2 State Key Laboratory of Ecological Pest Control for Fujian and Taiwan Crops, Fujian Agriculture \& Forestry University, Fuzhou, Fujian, China \\ 3 Fujian-Taiwan Joint Centre for Ecological Control of Crop Pests, Fujian Agriculture and Forestry University, Fuzhou, Fujian, China \\ ${ }^{4}$ Graham Centre for Agricultural Innovation, Charles Sturt University, Orange, New South Wales, Australia \\ Corresponding Author: Geoff M Gurr \\ Email address: ggurr@csu.edu.au
}

Conservation biological control emphasizes natural and other non-crop vegetation as a source of natural enemies to focal crops. There is an unmet need for better methods to identify the types of vegetation that are optimal to support specific natural enemies that may colonize the crops. Here we explore the commonality of the spider assemblage considering abundance and diversity $(H)$ - in brassica crops with that of adjacent non-crop and non-brassica crop vegetation. We employ spatial-based multivariate ordination approaches, hierarchical clustering and spatial eigenvector analysis. The small-scale mixed cropping and high disturbance frequency of southern Chinese vegetation farming offered a setting to test the role of alternate vegetation for spider conservation. Our findings indicate that spider families differ markedly in occurrence with respect to vegetation type. Grassy field margins, non-crop vegetation, taro and sweetpotato harbour spider morphospecies and functional groups that are also present in brassica crops. In contrast, pumpkin and litchi contain spiders not found in brassicas, and so may have little benefit for conservation biological control services for brassicas. Our findings also illustrate the potential utility of advanced statistical approaches for identifying spatial relationships of species and identify the land uses most likely to offer alternative habitats for spider conservation biological control efforts and generates testable hypotheses for future studies. 
1 Multivariate ordination identifies vegetation types associated with spider conservation in

2 brassica crops

3 Hafiz Sohaib Ahmed Saqib ${ }^{1,2}$, Min-Sheng You ${ }^{1,2,3,4}$ and Geoff M. Gurr 1,2,3, 5, *

4

5

6

\author{
${ }^{1}$ State Key Laboratory of Ecological Pest Control for Fujian and Taiwan Crops, Fujian Agriculture \\ and Forestry, University, Fuzhou 35002, China \\ 2 Institute of Applied Ecology, Fujian Agriculture and Forestry, University, Fuzhou 35002, China \\ ${ }^{3}$ Fujian-Taiwan Joint Centre for Ecological Control of Crop Pests, Fujian Agriculture and Forestry \\ University, Fuzhou 35002, China \\ 4 Key Laboratory of Integrated Pest Management for Fujian-Taiwan Crops, Ministry of \\ Agriculture, Fuzhou 35002, China \\ ${ }^{5}$ Graham Centre, Charles Sturt University, Orange, NSW 2800, Australia \\ ${ }^{*}$ Corresponding author, e-mail: ggurr@,csu.edu.au
}

Conservation biological control emphasizes natural and other non-crop vegetation as a source of natural enemies to focal crops. There is an unmet need for better methods to identify the types of vegetation that are optimal to support specific natural enemies that may colonize the crops. Here we explore the commonality of the spider assemblage - considering abundance and diversity $(H)$ - in brassica crops with that of adjacent non-crop and non-brassica crop vegetation. We employ spatial-based multivariate ordination approaches, hierarchical clustering and spatial eigenvector analysis. The small-scale mixed cropping and high disturbance frequency of southern Chinese vegetation farming offered a setting to test the role of alternate vegetation for spider conservation. Our findings indicate that spider families differ markedly in occurrence with respect to vegetation type. Grassy field margins, non-crop vegetation, taro and sweetpotato harbour spider morphospecies and functional groups that are also present in brassica crops. In contrast, pumpkin and litchi contain spiders not found in brassicas, and so may have little benefit for conservation 
28 biological control services for brassicas. Our findings also illustrate the potential utility of

29 advanced statistical approaches for identifying spatial relationships of species and identify the land

30

31

32 uses most likely to offer alternative habitats for spider conservation biological control efforts and generates testable hypotheses for future studies.

\section{INTRODUCTION}

In recent decades, anthropogenic activities - such as land clearing, environmental pollution and agricultural intensification - have led to adverse effects on the occurrence, diversity and evenness (Bengtsson et al. 2005; Benton et al. 2003; Landis et al. 2000; Sunderland \& Samu 2000; Thies et al. 2011; Thies \& Tscharntke 1999), and even the outright extinction of numerous species (Thomas et al. 2004). Biodiversity loss due to agricultural intensification is not merely driven by increases in the non-judicious use of hazardous fertilizers and pesticides (Geiger et al. 2010; Roubos et al. 2014), but also the landscape simplification and fragmentation, and the loss of habitat on which many species rely. To limit the use of chemical inputs and to fulfill the food demands of a growing worldwide population, researchers and growers have shifted their attention to the development of effective integrated pest management (IPM) tactics by manipulating the cultural farming practices including vegetation patterns (Gurr et al. 2016; Gurr et al. 2017; Landis et al. 2000), often specifically to conserve biological control agents (Fiedler et al. 2008; Liu et al. 2014; Pedigo \& Rice 2014).

Habitat management has long been used to promote beneficial arthropods in agroecosystems for the delivery of ecosystem services, particularly biological pest control (Gurr et al. 2017). The addition of non-crop vegetation to a crop system is effective in enhancing local densities of 
50 predators and parasitoids but is often not readily compatible with farming practices and may reduce

51 yields by reducing the area sown to the crop (Letourneau et al. 2011). An alternative approach is

52 to manipulate the availability of nearby donor habitat in field margins or adjacent fields and

53 uncropped zones. This avoids the need to reduce to the extent of the focal crop. There is a need,

54 however, to develop approaches that will help understand specific interactions between crops,

55 adjacent vegetation types and natural enemies (predators and parasitoids) (Furlong 2015; Furlong

56 et al. 2008; Furlong \& Zalucki 2010; Szendrei et al. 2014; Tscharntke et al. 2012).

57 Addressing the foregoing challenge has been methodologically difficult but population and

58 community ecology have entered an exciting phase of pattern unification (Blanchet et al. 2008;

59 Legendre \& Gauthier 2014). As the importance of spatial ecological models has become better

60 understood (Legendre \& Fortin 1989; Legendre \& Gauthier 2014), it has become increasingly clear

61 that ecologists need to incorporate these spatial distribution patterns into their ecological models.

62 There have been a number of methodological developments in ecology to investigate the influence

63 of environmental gradients on species' spatial distribution patterns (Legendre \& Gauthier 2014),

64 for example incorporation of geostatistical tools to explain geographical variation of species

65 (Peterson et al. 2007). Spatial autocorrelation analysis is more robust and forgiving of lower

66 sample sizes and missing data that often accompany agroecological studies, compared with the

67 classical geostatistical approaches (e.g. semivariograms) (Blanchet et al. 2008; Legendre \&

68 Gauthier 2014). There are several reasons to measure spatial autocorrelation in studies of this

69 nature. First, it indexes the nature and extent to which fundamental statistical assumptions are

70 violated, and, in turn, indicates the degree to which conventional statistical inferences are

71 compromised. It also signifies the presence of and quantifies the extent of redundant information

72 in georeferenced data, which in turn affects the information contribution of each georeferenced 
73 observation to statistics calculated with a database. More fundamentally, the measurement of

74 spatial autocorrelation describes the overall patterns across a geographic landscape, supporting

75 spatial prediction and allowing detection of striking deviations (Griffith 2013).

76 Spiders (Araneae) are an invariably abundant and dominant, species-rich guild of predators in crop

77 fields (Marc et al. 1999; Nyffeler \& Sunderland 2003; Schmidt et al. 2003; Schmidt \& Tscharntke

78 2005). Characteristically, few spider taxa achieve dominance on agricultural lands, and they have

79 been referred to as "agrobionts" (Marc et al. 1999; Samu \& Szinetár 2002) and can play a vital

80 role not only as generalist predators in suppressing the pest densities, but also as specialist

81 predators of key pest species. For example, Chapman et al. (2013) showed that spider species are

82 not truly polyphagous, but exhibit the specialized feeding habits by feeding on jumping prey items

83 such as Collembola or slowly-crawling prey such as aphids. The results of another study also

84 suggested that manipulating spider community composition to give complementary functional

85 groups (i.e. foliage-hunters Xysticus cristatus (Thomisidae) and the ground-hunters Pardosa

86 palustris (Lycosidae)), can give a better biological control compared with conserving predator

87 biodiversity per se which can occur without necessarily increasing functional diversity (Birkhofer

88 et al. 2008). Earlier work, Riechert \& Lawrence (1997); Riechert \& Bishop (1990), showed that

89 the significant effect of spiders on the suite of pests in a mixed vegetable cropping systems was an

90 assemblage effect, rather than the effect of just a few dominant spider species. It can, therefore, be

91 important to focus conservation biological control efforts relatively broadly across multiple natural

92 enemy functional groups.

93 It is, however, not clear if spider species utilise agricultural habitat in general or exhibit specificity

94 to crop and non-crop habitats on farms. This has clear and important ramifications for the extent

95 to which spiders utilize a diversity of crop types and non-crop vegetation as source habitat when 
96 colonizing a focal crop of interest. This study was designed to explore the extent of the similarity

97 between spider assemblages in brassica crops and different types of adjacent (non-brassica) crop

98 and non-crop vegetation, and to explore the influence of various adjacent vegetation types on the

99 spatial distribution of spiders. Specifically, we hypothesized that abundance and diversity -

100 including functional groups - of spiders would differ among vegetation types represented in a in

101 brassica-production landscape, that some vegetation types would have spider assemblages similar

102 to that of brassica crops, and that this would indicate the potential value of this vegetation as

103 donor habitat from which spiders could move to colonise a newly planted brassica crop or to

104 repopulate after a disturbance event.

\section{MATERIALS AND METHODS}

\section{Experimental Design and Sampling}

107 Spiders were sampled in brassica crops and adjacent vegetation types in three sites in Fujian

108 Province, China. Two sites were located in the Nantong district $\left(25^{\circ} 55^{\prime} 13.97^{\prime \prime} \mathrm{N}, 119^{\circ} 15^{\prime} 42.15^{\prime \prime} \mathrm{E}\right.$

$109 \& 25^{\circ} 55^{\prime} 0.25^{\prime \prime} \mathrm{N}, 119^{\circ} 15^{\prime} 39.46^{\prime \prime}$, respectively) and a third in the Minqing district $\left(26^{\circ} 10^{\prime} 4.72^{\prime \prime}\right.$

110 N-118 $46^{\prime} 18.08^{\prime \prime}$ E), of greater Fuzhou City. Each site comprised a focal brassica field and the

111 adjacent vegetation types (comprised of both crop and non-crop habitats) within an approximate

11250 x 50 m grid. Adjacent crop habitats included litchi, pumpkin, sweetpotato and taro; whilst non-

113 crop habitat types consisted of adjacent field margins and fallow fields (both containing a variety

114 of grasses, forbs and some bare ground) as well as non-crop vegetation with small woody

115 perennials. The three sites were typical of smallholder farming in southeastern China and common

116 in other agricultural systems globally. All of the agronomic practices - including fertilizer inputs

117 and (frequent) pesticide application - were carried out as per normal by the host farmers. 
118 At each site, spiders were sampled from at least 25 and up to 29 grid points (Minqing $\mathrm{n}=29$ points,

119 Nantong $1 \mathrm{n}=25$ points, Nantong $2 \mathrm{n}=27$ points) (at least $10 \mathrm{~m}$ apart) extending across adjacent

120 vegetation types to the brassica field. Samples were collected on five occasions from August and

121 December of 2015, using a motorized blower-vacuum sampler (YAHAMA-EBV260) with a

122 removable net bag mounted in the inlet (Lee et al. 2014; Lin et al. 2016; Whitehouse et al. 2005).

123 A major typhoon in October completely flooded fields, which severely affected the population

124 dynamics of spiders. Two sampling events before typhoon were considered for analysis, while

125 three sampling occasions collected after the typhoon were not considered in the analysis, as spider

126 abundances were very low. Samples were collected at each grid point by running the vacuum

127 sampler for 2 minutes within an area of $2 \mathrm{~m}^{2}$. Sample bags were labeled and transferred to an ice

128 box to prevent predation and sample degradation, and taken to the laboratory for sorting and

129 identification under a stereo microscope. All of the samples were kept in 95\% ethanol (EtOH) for

130 preservation. Adults and immatures were identified to family level and assigned to the

131 morphospecies using BOLD taxonomic classifications (Ratnasingham \& Hebert 2007) and a

132 morphological key (Carl 2016). Global Positioning System (GPS) data of xy-coordinates were

133 recorded using GARMIN GPS device (GPSMAP® 60CSx).

\section{Statistical Analysis}

135 To test the importance of vegetation types on spider assemblages in brassica fields and the 136 influence of those habitats on the spatial distribution of spider species, we applied variance

137 partitioning, hierarchical clustering (for community similarities or dissimilarities) and spatial 138 eigenvector analysis for spider abundance and diversity data. Abundance " $n$ " and Shannon-Wiener 139 index " $H$ ” (Shannon et al. 1949) were calculated using the vegan package (vegan 2.4-0) (Oksanen 140 et al. 2016), in R statistical software ( $\mathrm{R}$ version 3.4.0), then the data were Hellinger transformed 
141 to obtain normality and adjust variance prior to multivariate analysis. The Hellinger transformation

142 has good statistical properties to test for relationships among explanatory variables and draw

143 biplots in constrained or unconstrained multivariate ordination (e.g. redundancy analysis RDA)

144 without resorting to the Euclidean distances (Legendre \& Gallagher 2001) and is also suited to

145 data sets with multiple zero values. We identified the response of spider abundance and diversity

$146(H)$ against different vegetation types and weighted principal coordinates of neighbor matrices

147 (PCNM) as explanatory variables using the "varpart" and "pcnm" functions of package "vegan"

148 (version 2.4-1) (Oksanen et al. 2016) in R (version 3.4.0), which allowed variance partitioning to

149 separate the effects of weighted PCNM and vegetation types on spider abundance and diversity

150 (H) (Peres-Neto et al. 2006). PCNM, also known as Moran's Eigenvector Maps (MEM), is a

151 powerful approach able to detect spatial or temporal patterns (henceforth, only spatial patterns will

152 be discussed) of varying scale in response data (spider abundance and diversity) (Borcard \&

153 Legendre 2002; Borcard et al. 2004; Dray et al. 2006). Essentially, spatial variables are used to

154 determine the distance between sites with special focus on neighbouring sites. Additionally, the

155 "rda" function of package "vegan" (version 2.4-1) was used to test the significance of fractions of

156 each spider family's abundance and diversity $(H)$, and triplots were constructed to visualize the

157 vegetation types associated with different spider families. All analyses was carried out separately

158 for each of the three experimental sites because of differences in adjacent vegetation types to the 159 brassica field.

160 To measure community dissimilarities of spiders in different vegetation types, hierarchical

161 clustering was carried out for the abundance and diversity $(H)$ per sampling points at each

162 experimental site. A quantitative version of the Sørensen index, Bray-Curtis dissimilarity was used

163 to measure the percentage differences and to construct dissimilarity matrices for abundance and 
164 diversity $(H)$ of spider families in brassica and adjacent crop and non-crop habitat types using the

165 "vegdist" function with "method = "bray"” (Aanderud et al. 2015; Jeremy 2013) using "vegan"

166 (version 2.4-1) (Oksanen et al. 2016). We visualized the $\beta$-dissimilarity matrix using heatmap for

167 the abundance and diversity $(H)$ of spider families at each of the experimental sites (Aanderud et

168 al. 2015; Jeremy 2013; Murtagh \& Legendre 2014) by using the "gplots"(Gregory et al. 2016),

169 "Heatplus"(Ploner 2015), "RColorBrewer"(Neuwirth 2014) and "ComplexHeatmap"(Gu et al.

170 2016) packages in $\mathrm{R}$ (version 3.4.0). An assessment of the uncertainty in the cluster delineation

171 was done through multiscale nonparametric bootstrap resampling tests (Shimodaira 2002) using

172 “pvclust”(Suzuki \& Shimodaira 2013) package in R (version 3.4.0). This helps to determine $p$ -

173 values (two types: approximately unbiased (AU) $p$-value and bootstrap probability (BP) value) of

174 each cluster in the hierarchy (Suzuki \& Shimodaira 2006).

175 Spatial eigenvector analysis is particularly well suited to data with low spatial or temporal

176 replication, when compared to classical geostatistical analysis (e.g. semivariograms) (Peres-Neto

177 \& Legendre 2010; Perović \& Gurr 2012), which was the case in our data. We were interested in

178 calculating and mapping the spatial variation in the occurrence of spiders, and analyzing its

179 relationship with the adjacent vegetation of the focal brassica field. Distance-based MEM

180 (dbMEM) (Borcard et al. 2004; Legendre \& Gauthier 2014) was used to control for spatial

181 autocorrelation in tests of abundance and diversity $(H)$ of spider-vegetation relationships, (see

182 Griffith \& Peres-Neto (2006) using the packages “adespatial” (Stéphane et al. 2017), "ade4”

183 (Chessel et al. 2009), “adegraphics” (Stéphane \& Aurélie 2017) in R (version 3.4.0). We identified

184 a total of 11 distance based Moran's eigenvector maps for Minqing, seven for Nantong 1 and nine

185 for Nantong 2. Significant Moran's eigenvector maps for each of the experimental sites were

186 identified with forward selection using double stop criterion (Blanchet et al. 2008), $\alpha=0.05$ and 
$187 \mathrm{R}^{2}$ values (for abundance; $\mathrm{R}^{2}=0.45$ in Minqing, $\mathrm{R}^{2}=0.37$ in Nantong 1 and $\mathrm{R}^{2}=0.34$ in Nantong

188 2, and for diversity $(H) ; \mathrm{R}^{2}=0.46$ in Minqing, $\mathrm{R}^{2}=0.34$ in Nantong 1 and $\mathrm{R}^{2}=0.23$ in Nantong 2).

189 We identified one significant Moran's eigenvector map for spider abundance out of a total of 11 in

190 Minqing and nine for Nantong 2. Whilst for diversity $(H)$; we identified two significant Moran's

191 eigenvector maps out of total 11 in Minqing and one out of nine for Nantong 2. Further, canonical

192 analysis (rda) was performed to compute the dbMEM spatial models and the "anova" function was

193 used to test the significance of these models. All spatial models were found to be highly significant

194 ( $p$-value $<0.001)$. R-codes and datasets are attached as Supplementary data 1.

\section{RESULTS}

196 A total of 919 (461-Minqing, 216-Nantong 1 and 242 at Nantong 2) spider individuals were 197 captured, representing 48 morphospecies across nine families. In Minqing, variance partitioning 198 results showed that vegetation type (X1) alone explained 13\% of variation in abundance of spiders, 199 and the total effect of X1 and PCNM (X2) was 6\% (Fig 1a). On the other hand, 5\% of variation in 200 diversity $(H)$ of spiders at Minqing alone explained by the variable X1, and $20 \%$ of variation explained by the X1+X2 (intercept), whilst the total effect of both variables X1 and X2 was 16\%

202 (Fig 1b). The 23\% of variation in spider diversity at Nantong 1 alone explained by the X2 and 14\% 203 by the variable X1, whilst total effect both X1 and X2 was $44 \%$ of total variation (Fig 1c). In Nantong 1 , only $2 \%$ of total variation in spider diversity explained by the marginal effect of 205 variable X1 (Fig 1d).

RDA analysis (for testing the significance of each variance fraction) revealed strong effects of vegetation types (X1) and weighted PCNM (X2) on the abundance of different spider families in Minqing $\left(\mathrm{R}^{2}=26 \%\right.$, adj $\left.\mathrm{R}^{2}=13 \%\right)$, but the overall significance of the model was lower $(p$-value $=$ 0.07). Similarly, predictors $X 1$ and $X 2$ also showed strong effects for spider diversity $(H)$ in 
210 Minqing $\left(\mathrm{R}^{2}=19 \%\right.$, adjR $\left.\mathrm{R}^{2}=14 \%\right)$ with lower significance of the overall model $(p$-value $=0.28)$. In

211 Nantong 1, rda analysis showed strong effects of predictors X1 and X2 on the diversity $(H)$ of

212 spiders $\left(\mathrm{R}^{2}=18 \%\right.$, adj $\left.\mathrm{R}^{2}=05 \%\right)$ with lower significance of the overall model ( $p$-value $\left.=0.11\right)$.

213 Whilst, predictors X1 and X2 had less effects on diversity $(H)$ of spiders in Nantong $2\left(\mathrm{R}^{2}=10 \%\right.$,

$\left.214 \operatorname{adj} \mathrm{R}^{2}=-03 \%\right)$ with very low significance of the global model ( $p$-value $\left.=0.57\right)$. RDA ordination

215 showed that non-crop vegetation strongly supports the abundance of Linyphiidae and Salticidae at

216 Minqing, while taro had particularly high in abundance of Araneidae, Oxyopidae, Tetragnathidae,

217 Theridiidae and Thomisidae (Fig 2). In Minqing, rda ordination for diversity $(H)$ illustrated strong

218 association of Thomisidae and Oxyopidae with non-crop vegetation, Salticidae and Lycosidae with

219 fallow land, and taro, in contrast, had high diversity $(H)$ of Araneidae, Tetragnathidae and

220 Theridiidae (Fig 3a). However, in Nantong1, non-crop vegetation held a greater diversity $(H)$ of

221 Araneidae (Fig 3b), and Oxyopidae in Nantong 2 (Fig 3c). Sweetpotato exhibited greater diversity

222 of Tetragnathidae and Lycosidae at Nantong 1 (Fig 3b), and Araneidae at Nantong 2 (Fig 3c).

223 Diversity of Oxyopidae showed strong positive association with Litchi in Nantong 1 (Fig 3b). The

224 field margins of brassica fields supported high diversity of Salticidae at Nantong 1 (Fig 3b) and of

225 Salticidae, Thomisidae and Lycosidae at Nantong 2 (Fig 3c).

226 Community similarity/dissimilarity analyses between vegetation types, showed that brassicas

227 share most of the spider families with other surrounding vegetation types in terms of abundance

228 (Fig 4a, S1a, S2a) and diversity $(H)$ (Fig 5a, S1b, S2b) (same colour in heatmap). The soil surface-

229 associated hunting Lycosidae, however, showed strong differences in abundance and diversity $(H)$

230 between different vegetation types in all experimental sites (Fig 4a, S3a, S4a). Additionally, to

231 assess the level of uncertainty in each cluster, the $p$-values (AU and BP) for each of the hierarchical

232 clusters were calculated using bootstrap resampling techniques. Attributes of spider family 
233 abundance and diversity $(H)$ are examined and hierarchical clustering performed. Values on the

234 edges of the clustering are $p$-values (\%). Red values are AU $p$-values and green values are BP $p$ -

235 values. Clusters with AU $p$-values $>95 \%$ are significantly supported by the abundance (Fig 4b, S1c,

236 S2c) and diversity data of spiders (Fig 5b, S1d, S2d). For example, abundance of spiders in

237 Minqing (Fig 4b), the cluster labelled 4 in Fig $4 b$ the observed AU $p$-values are 90\%, 96\%, 81\%

238 and 77\%, whilst, observed BP values are 44\%, 40\%, 43\%, and 37\%, respectively, and the cluster

239 dendrogram with $96 \%$ AU $p$-value were significantly supported by the spider abundance data.

240 Spatial autocorrelation patterns were found to be highly significant $(P<0.001)$ for abundance of

241 spiders in Minqing and Natong 2, and for diversity in Minqing and Nantong 1. The spatial

242 weighting matrix maps, based on the xy-coordinates of each sampling point, associated with the

243 dbMEM Eigenfunctions for Minqing, Nantong 1 and Nantong 2 are shown in Fig 6a, S3a and S4a,

244 respectively. The significant spatial correlation model for Minqing, indicated that brassicas, non-

245 crop vegetation, field margins, fallow land and taro were the vegetation types spatially associated

246 with greater spider abundance (Fig 6b) and diversity $(H)$ (Fig 6c). Similarly, for Nantong 2;

247 brassica, field margin, sweetpotato and non-crop vegetation were spatially associated with greater

248 spider abundance (Fig S3b). Moreover, significant spatial autocorrelation was found only for

249 spider diversity $(H)$ in Nantong 1; where litchi, sweetpotato and non-crop vegetation exhibited

250 strong positive spatial autocorrelation with the diversity $(H)$ of spiders (Fig S4b).

\section{DISCUSSION}

252 Mixed cropping systems that include perennial crops, non-cropped and non-sprayed zones, offer

253 a relatively stable environment, increasing the potential for alternative and source habitat for the

254 conservation of natural enemies (Blitzer et al. 2012; Marc \& Canard 1997; Rypstra et al. 1999;

255 Schmidt \& Tscharntke 2005). Among predator taxa that can be important are spiders that attack 
256 pests as diverse as Spodoptera littoralis (Mansour et al. 1980) and aphids (Birkhofer et al. 2008).

257 It is known that spider assemblages rather than individual, dominant species are important for pest

258 suppression (Riechert \& Lawrence (1997); Riechert \& Bishop (1990)) but - in contrast to non-

259 spider taxa - we currently have a poor understanding of how to manage agroecosystems to best

260 promote biological pest control by spiders. Moving beyond the generalization that non-crop

261 vegetation can potentially suppressing pest populations by promoting functionally different groups

262 of natural enemies (Bianchi et al. 2006; Boller et al. 2004; Gurr et al. 2017; Thies \& Tscharntke

263 1999) is a key challenge in applied ecology. Addressing this requires empirical evidence on the

264 effects of differing vegetation types on associated abundance and impact in nearby focal crops but

work of this type requires labour intensive surveys with associated laboratory sorting. Such field

work can also can be stymied by unexpected events such as floods that lead to small sample sizes suggest that more advanced statistical approaches offer the scope to deal with this dual challenge of ecology and data analysis.

In our study, spider community structure was clearly shown to vary among vegetation types. There was high variance observed for spider abundance among the different vegetation types at the scale

272 of a few meters from the brassica crops in Minqing, whilst spider diversity $(H)$ was mostly a 273 function of spatial distance and its combined effect with adjacent crop and non-crop habitats. These

274 results suggest the patchiness of spider distribution in brassica production systems and was much 275 stronger for cursorial families (Lycosidae and Thomisidae) as compared with web-builders 276 (Araneidae, Linyphiidae, Tetragnathidae), a finding that is broadly consistent with Blitzer et al.

277 (2012); Schmidt et al. (2003). This may reflect differences among the vegetation types for bare 278 ground would favour movement of cursorial spiders (ground-runners), unimpeded by vegetation 
279 structure. Whilst, vegetation type influenced spider abundance, diversity was less more strongly

280 influenced by weighted PCNM matrix (distance between sites with special focus on neighbouring

281 sites). This suggest that surrounding vegetation nearby the brassica field affects the spider

282 abundance at a local-scale (up to few meters from focal crop). This may relate to the structure and

283 permanence of vegetation types, both of which affect the scope for a given vegetation type to

284 provide alternative food or shelter resources and thereby drive the assemblage and diversity $(H)$ of

285 spiders (Langellotto \& Denno 2004; Schmidt \& Tscharntke 2005; Thies \& Tscharntke 1999).

286 Whilst some spider species tend to dominate predator communities in crop fields and are

287 considered as “agrobionts" (Samu \& Szinetár 2002), it is not clear if these species generally prefer

288 crop fields over other vegetation types and to what degree they may discriminate between crop

289 types. Specifically, in brassica agroecosystems with high levels of disturbance from insecticide

290 use, planting, and harvest events, adjacent crop and non-crop vegetation can play a vital role in the

291 local conservation of spiders. Our results illustrate that, for most of the spider families, abundance

292 is strongly associated with perennial or dense, bushy vegetation types (taro, non-crop vegetation

293 and pumpkin) nearby the brassica fields. This finding is in accordance with Schmidt et al. (2003);

294 Schmidt \& Tscharntke (2005) that adjacent perennial vegetation can strongly influence the

295 abundance and diversity of natural enemies. This may be because these vegetation types offer a

296 refuge from disturbance and in which alternative food sources are present (Halley et al. 1996;

297 Topping 1999; Topping \& Sunderland 1994). In contrast to abundance, patterns of spider diversity

$298(H)$ in our study demonstrate strong association of non-web building spiders (Lycosidae,

299 Salticidae, Thomisidae and Oxyopidae) with fallow land and brassica fields (e.g Carvalho \&

300 Cardoso (2014); Uetz et al. (1999)). This may be a consequence of their mode of hunting, since

301 such habitats have relatively large areas of bare ground for dispersal and foraging (Schmidt \& 
302 Tscharntke 2005). For web building families (Theridiidae, Araneidae, Tetragnathidae and 303 Linyphiidae), diversity showed a strong association with the taro, sweetpotato and non-crop 304 vegetation, which may be due to the availability of more relatively complex plant structures for 305 building webs, potentially complemented by the low disturbance regime of the fallow land 306 (Schmidt \& Tscharntke 2005; Thies \& Tscharntke 1999; Topping 1999). Overall, these results 307 suggested different habitat requirement for these two functional groups of spiders, further driving 308 resource differentiation. Distinct preferences, in terms of niche requirements for particular habitat 309 - composed of certain plant diversity - are known for spiders, (e.g. Bonte et al. (2002); Griffin et al. (2008)). Such preferences offer scope for manipulative use to promote the ecosystem services of biological control by spider functional groups that are the able to partition the prey resource and achieve high levels of suppression. These results provide a foundation for future research to further unravel the underlying mechanisms for the patterns observed here; for example, distribution and assemblage of spider species caused as a result of plant structural diversity in various cover types or caused by various agronomic practices and the role of broader landscape in aerial dispersion of 316 spiders.

317 In terms of advancing analytical approaches for handing data sets of the type dealt with here, 318 hierarchical clustering is shown to be a useful for measuring community dissimilarities. In this 319 study, we move beyond the measuring of diversity within the sites and we investigated the $\beta$ 320 diversity by assessing similarity of the spider assemblages among the sampled habitats (Aanderud et al. 2015; Warnes et al. 2009). Results of $\beta$-diversity analysis showed commonality in most of 322 the spider taxa abundance and diversity between brassica and adjacent crop and non-crop 323 vegetation types. This suggests that certain adjacent crops (taro, sweetpotato and pumpkin) and 324 non-crop habitats (non-crop vegetation and field margins) shared spider taxa with brassica fields, 
325 so these may provide especially useful refuges and serve as donor habitat for spiders spilling over

326 into brassica crops following a disturbance event such as replanting, insecticide use or flood.

327 The statistical approaches used in the present study show utility for extracting, from data sets of

328 modest size, testable hypotheses that can explore underlying mechanistic phenomena related to 329 spill-over patterns and confirm the relative importance of difference vegetation types as source

330 habitat for a given focal crop type. It is becoming necessary that ecologists incorporate spatial 331 autocorrelation patterns into ecological models, and the analysis of population dynamics, and 332 species distribution (Blanchet et al. 2008). Our results detected significant spatial autocorrelation 333 patterns between the numbers of spider individuals at different sampling points, and revealed 334 highly significant spatial correlations between the abundance of the spiders with field margins, 335 taro, non-crop vegetation and sweetpotato. The spatial eigenvectors method proved to be sensitive 336 for detecting spatial patterns in the present data despite it being constrained by natural factors. 337 Accordingly, our study also expands the methodological foundation for agroecological studies of 338 ecosystem providers for future research.

During the last few decades, the loss of biodiversity and ecosystem function in modern agroecosystems has been a major and growing concern of agroecological researchers (Bommarco et al. 2013; Ecosystem 2005; IPES-Food 2016; Potts et al. 2016). Our study illustrates the importance of non-crop plants nearby to crop fields to promote conservation biological control strategies for spiders and generates testable hypotheses for future studies. For example, there is a need to measure and track actual rates of spider movement between the habitat types used in the

345 present study, in order to determine if the predicted habitat types really are key donors of spider 346 colonization and recolonization for brassica crops. In addition, patterns of spider movement need 347 to be studied in relation to disturbance events. More generally, future research should extend to 
348 testing the temporal effects of farm management practices (i.e. cropping patterns, chemical inputs)

349 interacting with agricultural landscapes heterogeneity (compositional and configurational) on

350 organizational and functional levels of agroecosystem. These are the major factors which drive the

351 distribution, structure and composition of spider community in agroecosystems.

\section{REFERENCES}

353

354

355

356

357

358

359

360

361

362

363

364

365

366

367

368

369

370

371

372

373

374

375

376

Aanderud ZT, Jones SE, Fierer N, and Lennon JT. 2015. Resuscitation of the rare biosphere contributes to pulses of ecosystem activity. Frontiers in Microbiology 6:24. 10.3389/fmicb.2015.00024

Bengtsson J, Ahnström J, and Weibull A. 2005. The effects of organic agriculture on biodiversity and abundance: a meta-analysis. Journal of Applied Ecology 42:261-269. 10.1111/j.13652664.2005.01005.x

Benton TG, Vickery JA, and Wilson JD. 2003. Farmland biodiversity: Is habitat heterogeneity the key? Trends in Ecology \& Evolution 18:182-188. 10.1016/S0169-5347(03)00011-9

Bianchi FJ, Booij C, and Tscharntke T. 2006. Sustainable pest regulation in agricultural landscapes: a review on landscape composition, biodiversity and natural pest control. Proceedings of the Royal Society of London B: Biological Sciences 273:1715-1727.

Birkhofer K, Gavish-Regev E, Endlweber K, Lubin Y, Von Berg K, Wise DH, and Scheu S. 2008. Cursorial spiders retard initial aphid population growth at low densities in winter wheat. Bulletin of entomological research 98:249-255.

Blanchet FG, Legendre P, and Borcard D. 2008. Modelling directional spatial processes in ecological data. Ecological Modelling 215:325-336. 10.1016/j.ecolmodel.2008.04.001

Blitzer EJ, Dormann CF, Holzschuh A, Klein A-M, Rand TA, and Tscharntke T. 2012. Spillover of functionally important organisms between managed and natural habitats. Agriculture, ecosystems \& environment 146:34-43.

Boller EF, Häni F, and Poehling H-M. 2004. Ecological infrastructures: ideabook on functional biodiversity at the farm level: Landwirtschaftliche Beratungszentrale Lindau (LBL).

Bommarco R, Kleijn D, and Potts SG. 2013. Ecological intensification: harnessing ecosystem services for food security. Trends in Ecology \& Evolution 28:230-238. 10.1016/j.tree.2012.10.012 
377 Bonte D, Baert L, and Maelfait J-P. 2002. Spider assemblage structure and stability in a

378

379

380

381

382

383

384

385

386

387

388

389

390

391

392

393

394

395

396

397

398

399

400

401

402

403

404

405

406 heterogeneous coastal dune system (Belgium). Journal of Arachnology 30:331-343.

Borcard D, and Legendre P. 2002. All-scale spatial analysis of ecological data by means of principal coordinates of neighbour matrices. Ecological Modelling 153:51-68. 10.1016/S0304-3800(01)00501-4

Borcard D, Legendre P, Avois-Jacquet C, and Tuomisto H. 2004. Dissecting the spatial structure of ecological data at multiple scales. Ecology 85:1826-1832.

Carl TK. 2016. Guide to common spiders of Bakersfield, California. Department of Biology: California State University, Bakersfield.

Carvalho JC, and Cardoso P. 2014. Drivers of beta diversity in Macaronesian spiders in relation to dispersal ability. Journal of biogeography 41:1859-1870.

Chapman EG, Schmidt JM, Welch KD, and Harwood JD. 2013. Molecular evidence for dietary selectivity and pest suppression potential in an epigeal spider community in winter wheat. Biological Control 65:72-86.

Chessel D, Dufour A-B, and Dray S. 2009. Analysis of Ecological Data: Exploratory and Euclidean methods in Environmental sciences. Version 14-14 2 October 2010; 1: 411.

Dray S, Legendre P, and Peres-Neto PR. 2006. Spatial modelling: a comprehensive framework for principal coordinate analysis of neighbour matrices (PCNM). Ecological Modelling 196:483-493.

Ecosystem AM. 2005. Ecosystems and human well-being: wetlands and water. World Resources Institute, Washington, DC 5.

Fiedler AK, Landis DA, and Wratten SD. 2008. Maximizing ecosystem services from conservation biological control: the role of habitat management. Biological Control 45:254-271. 10.1016/j.biocontrol.2007.12.009

Furlong MJ. 2015. Knowing your enemies: Integrating molecular and ecological methods to assess the impact of arthropod predators on crop pests. Insect Sci 22:6-19. 10.1111/17447917.12157

Furlong MJ, Ju KH, Su PW, Chol JK, Il RC, and Zalucki MP. 2008. Integration of endemic natural enemies and Bacillus thuringiensis to manage insect pests of Brassica crops in North Korea. Agriculture, Ecosystems \& Environment 125:223-238. 10.1016/j.agee.2008.01.003 
407 Furlong MJ, and Zalucki MP. 2010. Exploiting predators for pest management: the need for sound

408

409

410

411

412

413

414

415

416

417

418

419

420

421

422

423

424

425

426

427

428

429

430

431

432

433

434

435

436

ecological assessment. Entomologia Experimentalis et Applicata 135:225-236. 10.1111/j.1570-7458.2010.00988.x

Geiger F, Bengtsson J, Berendse F, Weisser WW, Emmerson M, Morales MB, Ceryngier P, Liira J, Tscharntke T, Winqvist C, Eggers S, Bommarco R, Part T, Bretagnolle V, Plantegenest M, Clement LW, Dennis C, Palmer C, Onate JJ, Guerrero I, Hawro V, Aavik T, Thies C, Flohre A, Hanke S, Fischer C, Goedhart PW, and Inchausti P. 2010. Persistent negative effects of pesticides on biodiversity and biological control potential on European farmland. Basic and Applied Ecology 11:97-105. 10.1016/j.baae.2009.12.001

Gregory R, Warnes B, and Lodewijk B. 2016. gplots: Various R programming tools for plotting data. $R$ package version 3 .

Griffin JN, De La Haye KL, Hawkins SJ, Thompson RC, and Jenkins SR. 2008. Predator diversity and ecosystem functioning: density modifies the effect of resource partitioning. Ecology 89:298-305. 10.1890/07-1220.1

Griffith DA. 2013. Spatial autocorrelation and spatial filtering: gaining understanding through theory and scientific visualization: Springer Science \& Business Media.

Griffith DA, and Peres-Neto PR. 2006. Spatial modeling in ecology: the flexibility of eigenfunction spatial analyses. Ecology 87:2603-2613.

Gu Z, Eils R, and Schlesner M. 2016. Complex heatmaps reveal patterns and correlations in multidimensional genomic data. Bioinformatics 32:2847-2849.

Gurr GM, Lu Z, Zheng X, Xu H, Zhu P, Chen G, Yao X, Cheng J, Zhu Z, Catindig JL, Villareal S, Van Chien H, Cuong LQ, Channoo C, Chengwattana N, Lan LP, Hai LH, Chaiwong J, Nicol HI, Perovic DJ, Wratten SD, and Heong KL. 2016. Multi-country evidence that crop diversification promotes ecological intensification of agriculture Nature Plants 2:16014. 10.1038/nplants.2016.14

Gurr GM, Wratten SD, Landis DA, and You M. 2017. Habitat management to suppress pest populations: Progress and prospects. Annual Review of Entomology 62:91-109. 10.1146/annurev-ento-031616-035050

Halley J, Thomas C, and Jepson P. 1996. A model for the spatial dynamics of linyphiid spiders in farmland. Journal of applied ecology:471-492. 
437 IPES-Food. 2016. From uniformity to diversity: a paradigm shift from industrial agriculture to

438

439

440

441

442

443

444

445

446

447

448

449

450

451

452

453

454

455

456

457

458

459

460

461

462

463

464

465

466

467

diversified agroecological systems. International Panel of Experts on Sustainable Food systems. www.ipes-food.org.

Jeremy Y. 2013. Making heatmaps with $\mathrm{R}$ for microbiome analysis. http://www.molecularecologist.com.

Landis DA, Wratten SD, and Gurr GM. 2000. Habitat management to conserve natural enemies of arthropod pests in agriculture. Annual Review of Entomology 45:175-201. 10.1146/annurev.ento.45.1.175

Langellotto GA, and Denno RF. 2004. Responses of invertebrate natural enemies to complexstructured habitats: a meta-analytical synthesis. Oecologia 139:1-10.

Lee SY, Kim ST, Jung JK, and Lee J-H. 2014. A comparison of spider communities in Bt and nonBt rice fields. Environmental Entomology 43:819-827. 10.1603/EN12259

Legendre P, and Fortin MJ. 1989. Spatial pattern and ecological analysis. Vegetatio 80:107-138. $10.1007 / \mathrm{bf} 00048036$

Legendre P, and Gallagher ED. 2001. Ecologically meaningful transformations for ordination of species data. Oecologia 129:271-280. 10.1007/s004420100716

Legendre P, and Gauthier O. 2014. Statistical methods for temporal and space-time analysis of community composition data. Proceedings of the Royal Society of London, Series B: Biological Sciences 281:20132728.

Letourneau DK, Armbrecht I, Rivera BS, Lerma JM, Carmona EJ, Daza MC, Escobar S, Galindo V, Gutierrez C, Lopez SD, Mejia JL, Rangel AMA, Rangel JH, Rivera L, Saavedra CA, Torres AM, and Trujillo AR. 2011. Does plant diversity benefit agroecosystems? A synthetic review. Ecological Applications 21:9-21. 10.1890/09-2026.1

Lin S, Vasseur L, and You MS. 2016. Seasonal variability in spider assemblages in traditional and transgenic rice fields. Environmental Entomology 45:537-546. 10.1093/ee/nvw002

Liu Y-Q, Shi Z-H, Zalucki MP, and Liu S-S. 2014. Conservation biological control and IPM practices in Brassica vegetable crops in China. Biological Control 68:37-46. 10.1016/j.biocontrol.2013.06.008

Mansour F, Rosen D, Shulov A, and Plaut H. 1980. Evaluation of spiders as biological control agents of Spodoptera littoralis larvae on apple in Israel. Acta Oecologica, Oecologia Applicata 1:225-232. 
468 Marc P, and Canard A. 1997. Maintaining spider biodiversity in agroecosystems as a tool in pest

469

470

471

472

473

474

475

476

477

478

479

480

481

482

483

484

485

486

487

488

489

490

491

492

493

494

495

496

497

498 control. Agriculture, ecosystems \& environment 62:229-235.

Marc P, Canard A, and Ysnel F. 1999. Spiders (Araneae) useful for pest limitation and bioindication. Agriculture, ecosystems \& environment 74:229-273.

Murtagh F, and Legendre P. 2014. Ward's hierarchical agglomerative clustering method: which algorithms implement ward's criterion? Journal of Classification 31:274-295.

Neuwirth E. 2014. RColorBrewer: ColorBrewer palettes. R package version 1.1-2.

Nyffeler M, and Sunderland KD. 2003. Composition, abundance and pest control potential of spider communities in agroecosystems: a comparison of European and US studies. Agriculture, ecosystems \& environment 95:579-612.

Oksanen J, Kindt R, Legendre P, O’Hara B, Simpson GL, Solymos P, Stevens MHH, and Wagner H. 2016. The vegan package (Community ecology package). R-Forge.

Pedigo LP, and Rice ME. 2014. Entomology and pest management. Long Grove, Illinois: Waveland Press.

Peres-Neto PR, Legendre P, Dray S, and Borcard D. 2006. Variation partitioning of species data matrices: estimation and comparison of fractions. Ecology 87:2614-2625.

Peres-Neto PR, and Legendre P. 2010. Estimating and controlling for spatial structure in the study of ecological communities. Global Ecology and Biogeography 19:174-184.

Perović DJ, and Gurr GM. 2012. Geostatistical analysis shows species-specific habitat preferences for parasitoids. Biocontrol Science and Technology 22:243-247.

Peterson EE, Theobald DM, and Ver Hoef JM. 2007. Geostatistical modelling on stream networks: developing valid covariance matrices based on hydrologic distance and stream flow. Freshwater Biology 52:267-279. 10.1111/j.1365-2427.2006.01686.x

Ploner A. 2015. Heatplus: Heatmaps with row and/or column covariates and colored clusters. $R$ package version 2 .

Potts SG, Imperatriz-Fonseca V, Ngo HT, Biesmeijer JC, Breeze TD, Dicks LV, Garibaldi LA, Hill R, Settele J, and Vanbergen AJ. 2016. The assessment report on pollinators, pollination and food production: summary for policymakers. Bonn, Germany: Secretariat of the Intergovernmental Science-Policy Platform on Biodiversity and Ecosystem Services.

Ratnasingham S, and Hebert PD. 2007. BOLD: The Barcode of Life Data System (http://www.barcodinglife.org). Molecular Ecology Resources 7:355-364. 
499 Riechert S, and Lawrence K. 1997. Test for predation effects of single versus multiple species of 500 generalist predators: spiders and their insect prey. Entomologia Experimentalis et $501 \quad$ Applicata 84:147-155.

502 Riechert SE, and Bishop L. 1990. Prey control by an assemblage of generalist predators: spiders 503 in garden test systems. Ecology 71:1441-1450.

504 Roubos CR, Rodriguez-Saona C, and Isaacs R. 2014. Mitigating the effects of insecticides on 505 arthropod biological control at field and landscape scales. Biological Control 75:28-38. $506 \quad$ 10.1016/j.biocontrol.2014.01.006

507 Rypstra AL, Carter PE, Balfour RA, and Marshall SD. 1999. Architectural features of agricultural 508 habitats and their impact on the spider inhabitants. Journal of Arachnology:371-377.

509 Samu F, and Szinetár C. 2002. On the nature of agrobiont spiders. Journal of Arachnology 30:389$510 \quad 402$.

511 Schmidt MH, Lauer A, Purtauf T, Thies C, Schaefer M, and Tscharntke T. 2003. Relative 512 513 importance of predators and parasitoids for cereal aphid control. Proceedings of the Royal Society of London B: Biological Sciences 270:1905-1909.

Schmidt MH, and Tscharntke T. 2005. The role of perennial habitats for Central European farmland spiders. Agriculture, ecosystems \& environment 105:235-242.

Shannon CE, Weaver W, Blahut RE, and Hajek

B. 1949. The mathematical theory of communication. Urbana Illinois, USA University of Illinois Press.

Shimodaira H. 2002. An approximately unbiased test of phylogenetic tree selection. Systematic biology 51:492-508.

Stéphane D, and Aurélie S. 2017. An S4 Lattice-Based Package for the Representation of Multivariate Data - Version 1.0-8. CRAN.

Stéphane D, Guillaume B, Daniel B, Guillaume G, Thibaut J, Guillaume L, Pierre L, Naima M, 523 and Helene HW. 2017. Multivariate Multiscale Spatial Analysis - version 0.0-8. CRAN.

Sunderland K, and Samu F. 2000. Effects of agricultural diversification on the abundance, distribution, and pest control potential of spiders: a review. Entomologia Experimentalis et Applicata 95:1-13.

Suzuki R, and Shimodaira H. 2006. Pvclust: an R package for assessing the uncertainty in hierarchical clustering. Bioinformatics 22:1540-1542. 
529 Suzuki R, and Shimodaira H. 2013. Hierarchical clustering with P-values via multiscale bootstrap 530 resampling. $R$ package.

531 Szendrei Z, Bryant A, Rowley D, Furlong MJ, Schmidt JM, and Greenstone MH. 2014. Linking 532 habitat complexity with predation of pests through molecular gut-content analyses. 533 Biocontrol Science and Technology 24:1425-1438. 10.1080/09583157.2014.944098

534 Thies C, Haenke S, Scherber C, Bengtsson J, Bommarco R, Clement LW, Ceryngier P, Dennis C, 535 Emmerson M, Gagic V, Hawro V, Liira J, Weisser WW, Winqvist C, and Tscharntke T. 536 2011. The relationship between agricultural intensification and biological control:

Thies C, and Tscharntke T. 1999. Landscape structure and biological control in agroecosystems. Science 285:893-895. 10.1126/science.285.5429.893

Thomas CD, Cameron A, Green RE, Bakkenes M, Beaumont LJ, Collingham YC, Erasmus BF, De Siqueira MF, Grainger A, Hannah L, Hughes L, Huntley B, Van Jaarsveld AS, Midgley GF, Miles L, Ortega-Huerta MA, Peterson AT, Phillips OL, and Williams SE. 2004. Extinction risk from climate change. Nature 427:145-148. 10.1038/nature02121

Topping C. 1999. An individual-based model for dispersive spiders in agroecosystems: simulations of the effects of landscape structure. Journal of Arachnology:378-386.

Topping C, and Sunderland K. 1994. A spatial population dynamics model for Lepthyphantes tenuis (Araneae: Linyphiidae) with some simulations of the spatial and temporal effects of farming operations and land-use. Agriculture, ecosystems \& environment 48:203-217. Crist TO, Dormann CF, Ewers RM, Frund J, Holt RD, Holzschuh A, Klein AM, Kleijn D, Kremen C, Landis DA, Laurance W, Lindenmayer D, Scherber C, Sodhi N, SteffanDewenter I, Thies C, van der Putten WH, and Westphal C. 2012. Landscape moderation of biodiversity patterns and processes - eight hypotheses. Biological Reviews 87:661-685. 10.1111/j.1469-185X.2011.00216.x

Uetz GW, Halaj J, and Cady AB. 1999. Guild structure of spiders in major crops. Journal of Arachnology:270-280. 
558 Warnes GR, Bolker B, Bonebakker L, Gentleman R, Huber W, Liaw A, Lumley T, Maechler M, 559 Magnusson A, and Moeller S. 2009. gplots: Various $R$ programming tools for plotting 560 data.

561 Whitehouse M, Wilson L, and Fitt G. 2005. A comparison of arthropod communities in transgenic $562 \mathrm{Bt}$ and conventional cotton in Australia. Environmental Entomology 34:1224-1241. 563 10.1603/0046-225x(2005)034[1224:Acoaci]2.0.Co;2

564

565 


\section{Figure legends}

Figure 1 Venn diagram for the fractions of variation obtained by variance partitioning of a response data set; "Y" = Hellinger transformed spider taxa (a) abundance at Minqing, (b) diversity $(H)$ at Minqing, (c) diversity $(H)$ at Nantong 1 and (d) diversity $(H)$ at Nantong 2; against two explanatory environmental variable matrices; "X1" =Vegetation type surrounding the brassica field and "X2" = Principle Coordinates of Neighborhood Matrix (PCNM) and their intercept.

Figure 2 RDA Triplot (RDA on a covariance matrix) of the spatial correlation between Hellinger transformed abundance of spider families and vegetation types surrounding the brassica field using PCNM as distance matrix. The arrow length and direction correspond to the variance that can be explained by the environmental and response variables. The direction of an arrow indicates the extent to which the given factor is influenced by each RDA variable. The perpendicular distance between abundance of spider families and environmental variable axes in the plot reflects their correlations. The smaller the distance, the stronger the correlation. Numbers represents the sampling points in figure.

Figure 3 RDA Triplot (RDA on a covariance matrix) of the spatial correlation between Hellinger transformed diversity $(H)$ of spider families and vegetation types surrounding the brassica field using PCNM as distance matrix (a) at Minqing, (b) at Nantong 1 and (c) at Nantong 2. The arrow length and direction corresponds to the variance that can be explained by the environmental and response variables. The direction of an arrow indicates the extent to which the given factor is influenced by each RDA variable. The perpendicular distance between abundance of spider families and environmental variable axes in the plot reflects their correlations. The smaller the distance, the stronger the correlation. Numbers represents the sampling points in figure.

Figure 4 (a) Heatmap based on hierarchical clustering using Bray-Curtis resemblance matrix of spider taxa abundance at Minqing, where; "BRAS" = Brassica, "PUMP" = pumpkin, "FAL" = fallow land, "TA" = taro, "NCV" = Non-crop vegetation, and "FM" = Field margin. (b) Cluster plot to test the goodness of hierarchical clustering for abundance of spider families at Minqing. Values at branches are approximately unbiased (AU) $p$-values (left), bootstrap probability (BP) values (right), and cluster labels (bottom). Clusters with $\mathrm{AU}>95$ are consider to be significant. 
Figure 5 (a) Heatmap based on hierarchical clustering using Bray-Curtis resemblance matrix of spider taxa Shannon diversity at Minqing, where; "BRAS" = Brassica, "PUMP" = pumpkin, "FAL" = fallow land, "TA" = taro, "NCV" = Non-crop vegetation, and "FM" = Field margin. (b) Cluster plot to test the goodness of hierarchical clustering for Shannon diversity of spider families at Minqing. Values at branches are approximately unbiased (AU) p-values (left), bootstrap probability (BP) values (right), and cluster labels (bottom). Clusters with AU $>95$ are consider to be significant.

Figure 6 (a) Map showing the 29 sampling points ( 10m apart) in Minqing computed using geographical sampling distance matrix. Bubble plot maps based on the forward selection to identify the significant dbMEM spatial model among all dbMEM eigenfunction models of spider's (b) abundance and (c) Shannon diversity; showing the relative importance of spider's abundance and diversity along with their spatial distribution; The size of the square box representing spider's abundance and diversity in each eigenvector, ranging from white (largest negative value) to black (largest positive value). 
(a)

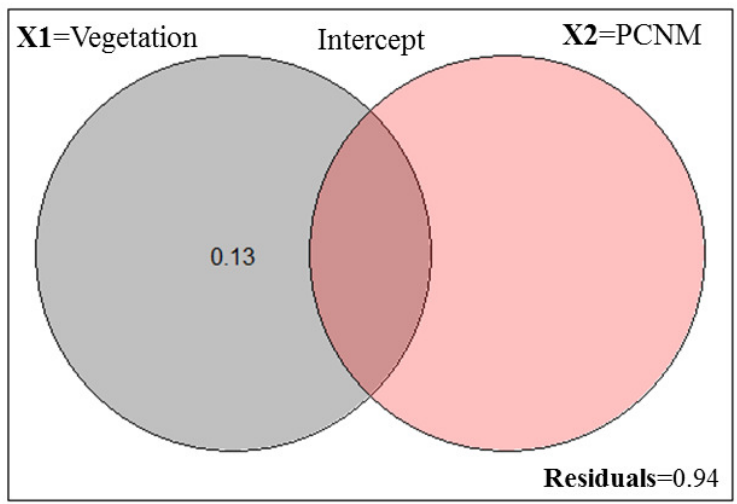

(c)

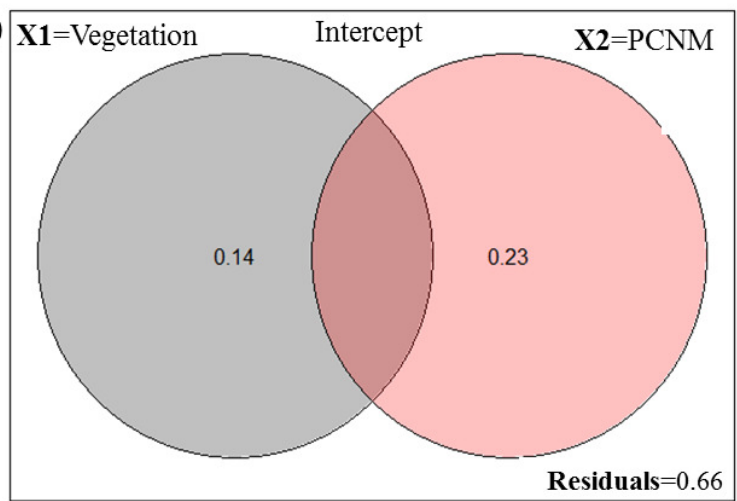

(b)

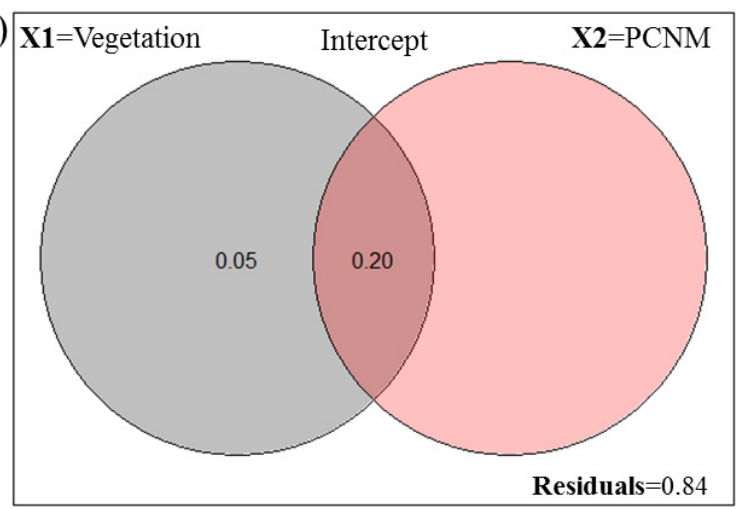

(d)

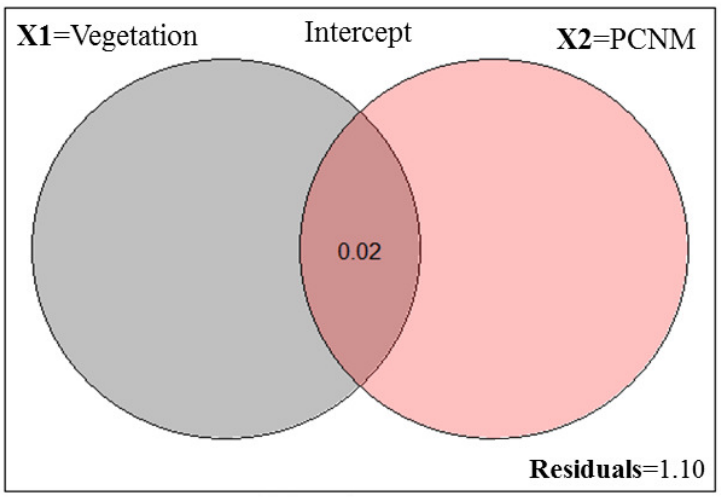

Figure 1 Venn diagram for the fractions of variation obtained by variance partitioning of a response data set; "Y" = Hellinger transformed spider taxa (a) abundance at Minqing, (b) diversity $(H)$ at Minqing, (c) diversity $(H)$ at Nantong 1 and (d) diversity $(H)$ at Nantong 2; against two explanatory environmental variable matrices; "X1" =Vegetation type surrounding the brassica field and "X2" = Principle Coordinates of Neighborhood Matrix (PCNM) and their intercept. 


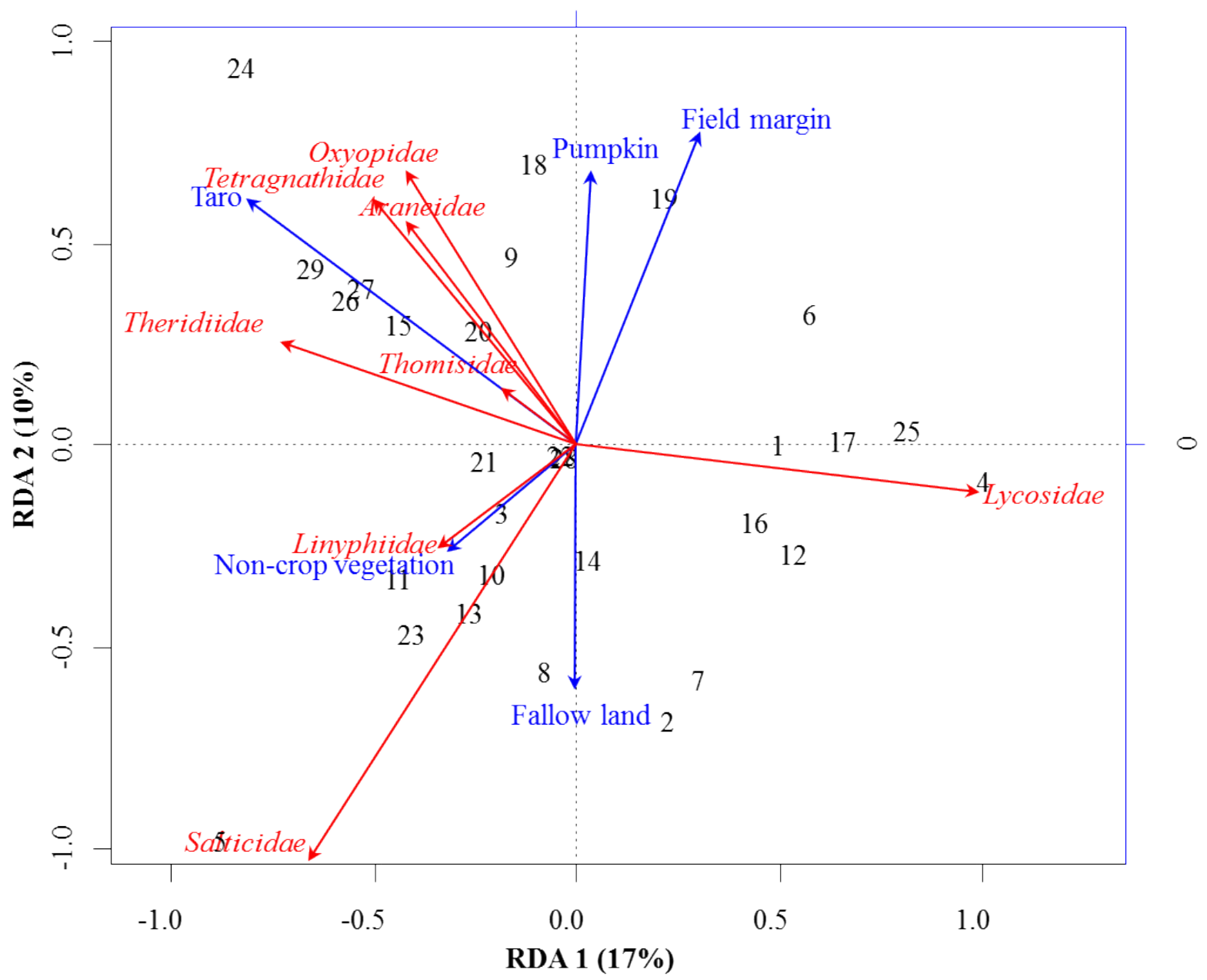

568

Figure 2 RDA Triplot (RDA on a covariance matrix) of the spatial correlation between Hellinger transformed abundance of spider families and vegetation types surrounding the brassica field using PCNM as distance matrix. The arrow length and direction correspond to the variance that can be explained by the environmental and response variables. The direction of an arrow indicates the extent to which the given factor is influenced by each RDA variable. The perpendicular distance between abundance of spider families and environmental variable axes in the plot reflects their correlations. The smaller the distance, the stronger the correlation. Numbers represents the sampling points in figure. 

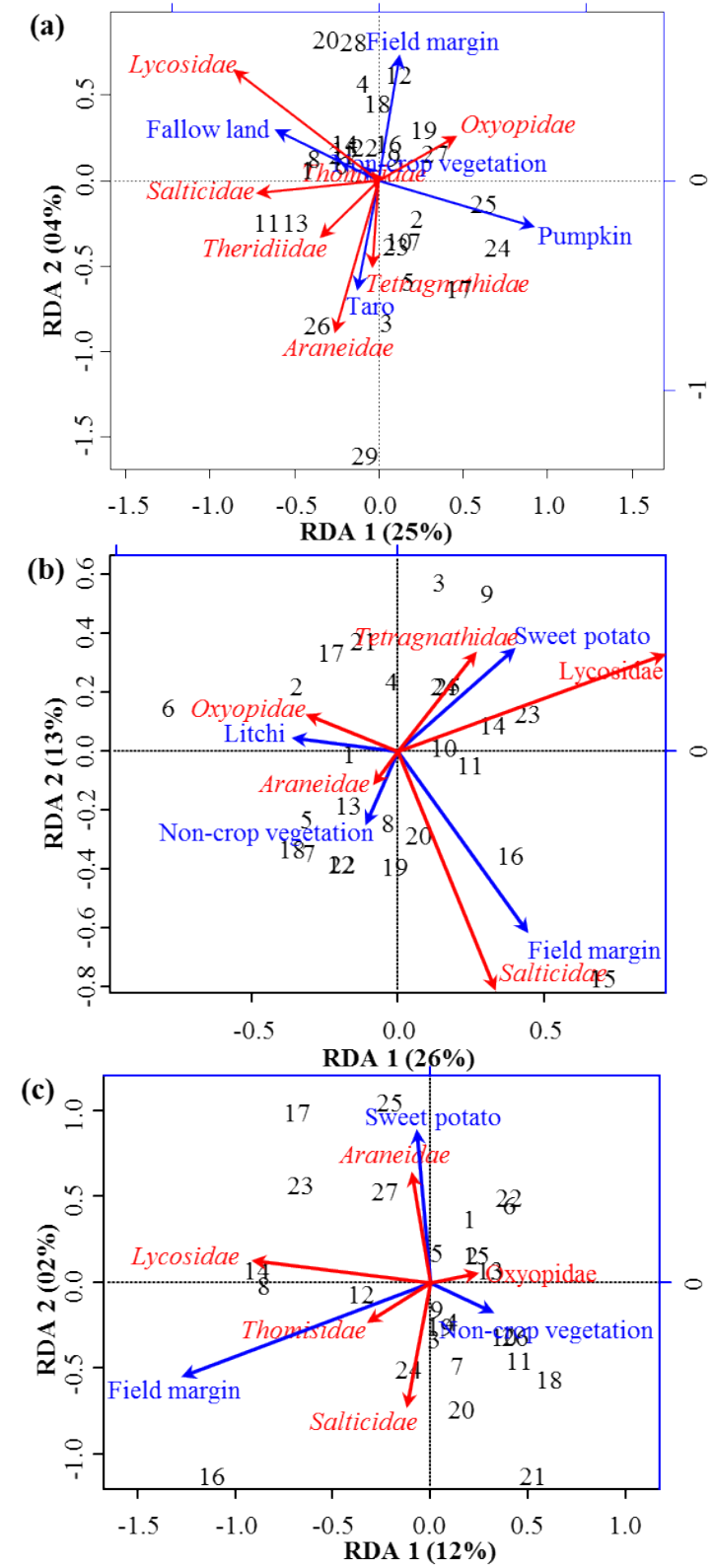

Figure 3 RDA Triplot (RDA on a covariance matrix) of the spatial correlation between Hellinger transformed diversity $(H)$ of spider families and vegetation types surrounding the brassica field using PCNM as distance matrix (a) at Minqing, (b) at Nantong 1 and (c) at Nantong 2. The arrow length and direction corresponds to the variance that can be explained by the environmental and response variables. The direction of an arrow indicates the extent to which the given factor is influenced by each RDA variable. The perpendicular distance between abundance of spider families and environmental variable axes in the plot reflects their correlations. The smaller the distance, the stronger the correlation. Numbers represents the sampling points in figure. 
(a)
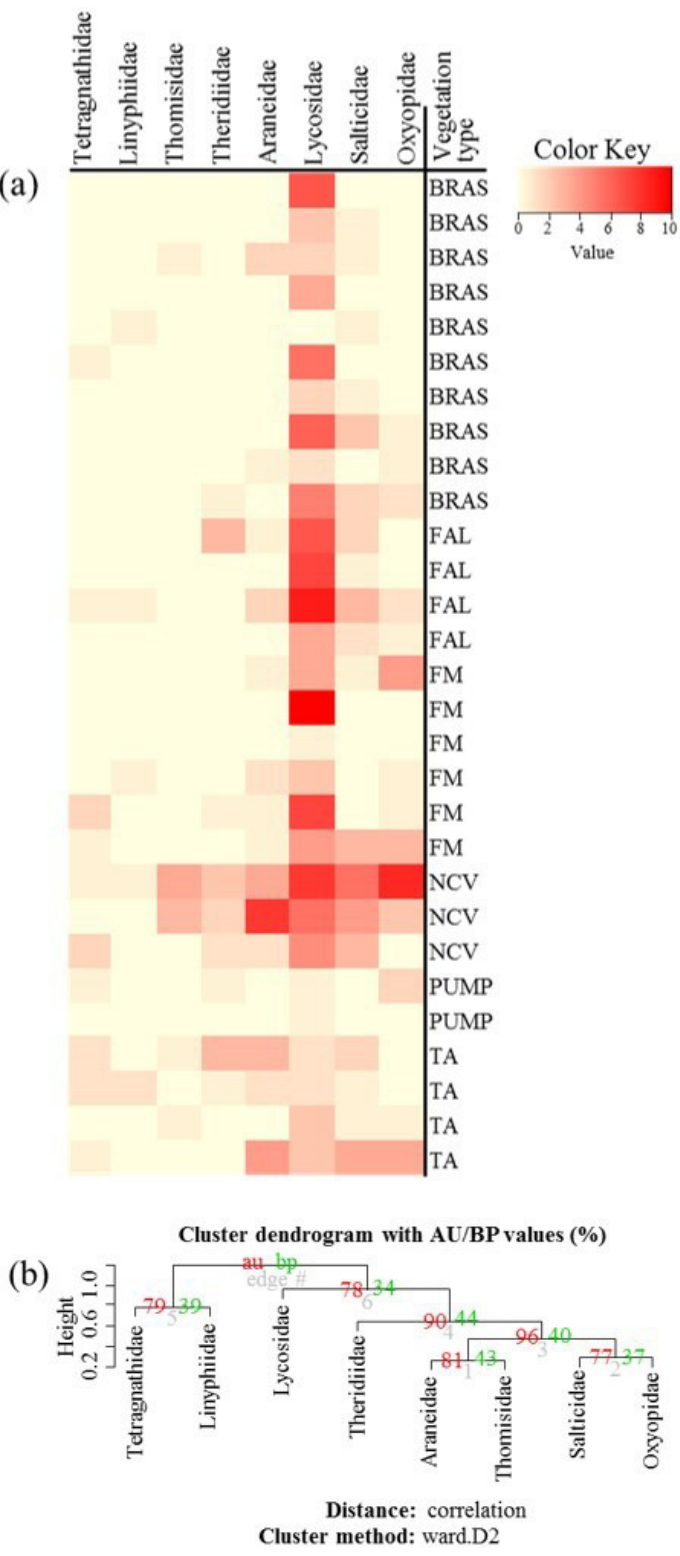

Figure 4 (a) Heatmap based on hierarchical clustering using Bray-Curtis resemblance matrix of spider taxa abundance at Minqing, where; "BRAS" = Brassica, "PUMP" = pumpkin, "FAL" = fallow land, "TA" = taro, "NCV" = Non-crop vegetation, and "FM" = Field margin. (b) Cluster plot to test the goodness of hierarchical clustering for abundance of spider families at Minqing. Values at branches are approximately unbiased (AU) p-values (left), bootstrap probability (BP) values (right), and cluster labels (bottom). Clusters with $\mathrm{AU}>95$ are consider to be significant. 
(a)

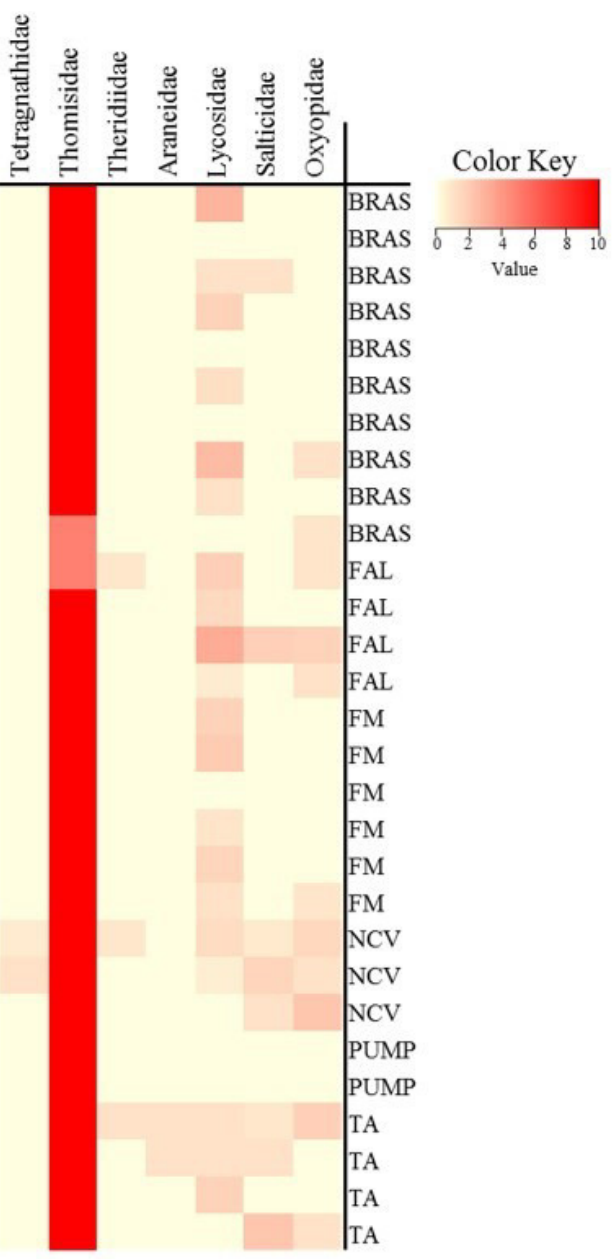

(b)

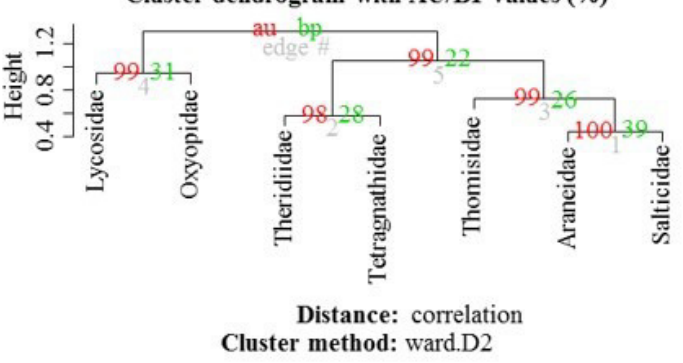

Figure 5 (a) Heatmap based on hierarchical clustering using Bray-Curtis resemblance matrix of spider taxa Shannon diversity at Minqing, where; "BRAS" = Brassica, "PUMP" = pumpkin, "FAL" = fallow land, "TA" = taro, "NCV" = Non-crop vegetation, and "FM" = Field margin. (b) Cluster plot to test the goodness of hierarchical clustering for Shannon diversity of spider families at Minqing. Values at branches are approximately unbiased (AU) p-values (left), bootstrap probability (BP) values (right), and cluster labels (bottom). Clusters with AU $>95$ are consider to be significant. 

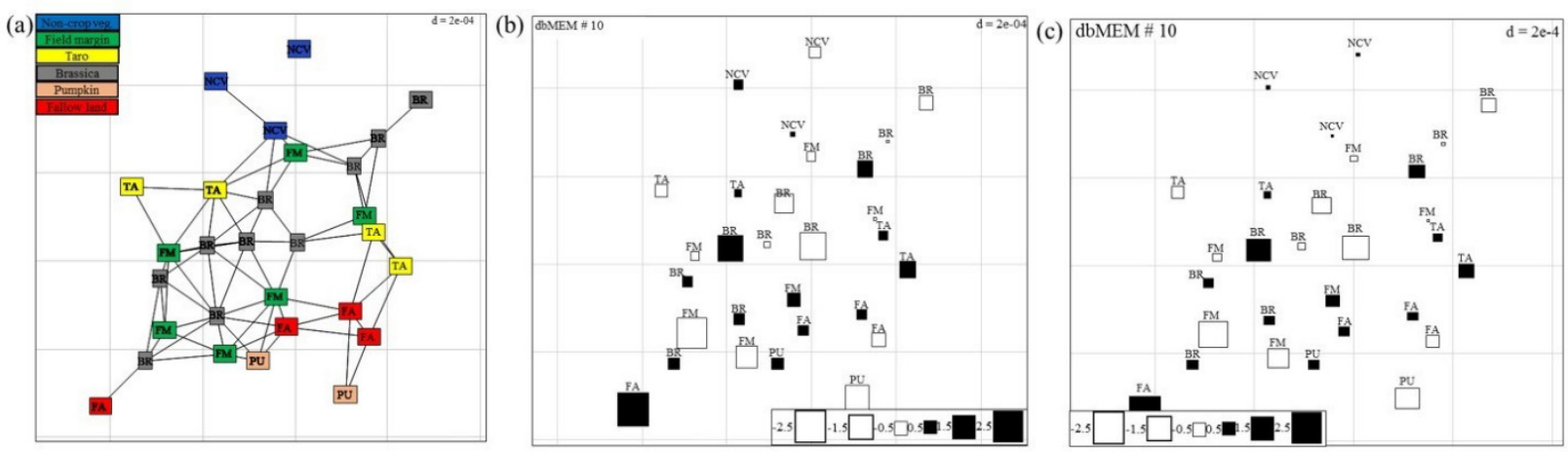

Figure 6 (a) Map showing the 29 sampling points ( 10m apart) in Minqing computed using geographical sampling distance matrix. Bubble plot maps based on the forward selection to identify the significant dbMEM spatial model among all dbMEM eigenfunction models of spider's (b) abundance and (c) Shannon diversity; showing the relative importance of spider's abundance and diversity along with their spatial distribution; The size of the square box representing spider's abundance and diversity in each eigenvector, ranging from white (largest negative value) to black (largest positive value). 